NBER WORKING PAPER SERIES

\title{
IS IT IS OR IS IT AIN'T MY OBLIGATION? \\ REGIONAL DEBT IN MONETARY UNIONS
}

\author{
Russell W. Cooper \\ Hubert Kempf \\ Dan Peled
}

Working Paper 10239

http://www.nber.org/papers/w10239

\author{
NATIONAL BUREAU OF ECONOMIC RESEARCH \\ 1050 Massachusetts Avenue \\ Cambridge, MA 02138 \\ January 2004
}

We are grateful to the CNRS and the NSF for financial support and to the late Louis Jordan from whom we freely borrowed the title. Cooper thanks the Research Department at the Federal Reserve Bank of Minneapolis for its support. Helpful comments and questions from Maria Alzua, Marco Bassetto, Micha Ben-Gad, Eddie Dekel, Patrick Kehoe, Todd Keister, Robert E. Lucas, John Shea, and Yoram Weiss, as well as seminar participants at the Federal Reserve Bank of Dallas, the Bank of Israel, the University of Maryland, Tel Aviv University, the University of Haifa, the Anglo-French seminar in macroeconomics, the European University Institute, the University of Pavia and the University of Bologna are very much appreciated. The views expressed herein are those of the authors and not necessarily those of the National Bureau of Economic Research.

(C2004 by Russell W. Cooper, Hubert Kempf, and Dan Peled. All rights reserved. Short sections of text, not to exceed two paragraphs, may be quoted without explicit permission provided that full credit, including (C) notice, is given to the source. 
Is it is or is it Ain't my Obligation? Regional Debt in Monetary Unions

Russell W. Cooper, Hubert Kempf, and Dan Peled

NBER Working Paper No. 10239

January 2004

JEL No. E610, E630, H770, F330

\title{
$\underline{\text { ABSTRACT }}$
}

This paper studies the implications of the circulation of interest bearing regional debt in a monetary union. Does the circulation of this debt have the same monetary implications as the printing of money by a central government? Or are the obligations of this debt simply backed by future taxation with no inflationary consequences? We argue here that both outcomes can arise in equilibrium. In the model economy we consider there are multiple equilibria which reflect the perceptions of agents regarding the manner in which the debt obligations will be met. In one equilibrium, termed Ricardian, the future obligations are met with taxation by a regional government while in the other, termed Monetization, the central bank is induced to print money to finance the region's obligations. The multiplicity of equilibria reflects a commitment problem of the central bank. A key indicator of the selected equilibrium is the distribution of the holdings of the regional debt. We use the model to assess the impact of policy measures, such as fiscal restrictions, within a monetary union.

\author{
Russell Cooper \\ Department of Economics \\ University of Texas \\ Austin, TX 78712 \\ and NBER \\ cooper@eco.utexas.edu \\ Hubert Kempf \\ EureQua, Universite Paris-1 Panthoen-Sorbonne \\ 106 Boulevard de 1'Hopital \\ F-75013 Paris, France \\ hubert.kempf@univ-paris1.fr \\ Dan Peled \\ Department of Economics \\ University of Haifa \\ Haifa 31905, Israel \\ dpeled@econ.haifa.ac.il
}




\section{Motivation}

This paper studies the inflationary implications of regional debt in a federation. Consider a federation of regions (states) in which monetary policy is centralized but fiscal policy is determined at the regional level. Individual countries, such as Argentina and the U.S., fit this description as does a coalition of countries which delegate monetary policy to a single central bank, such as the European Monetary Union.

The recent experience in Argentina motivates an analysis of the link between regional debt and inflation. The Argentine province of Buenos Aires circulated about 1.8 billion pesos of interest bearing provincial bonds starting in July 2001, during the currency board regime in Argentina. In fact, the notes comprising this debt, called Patacones, were of small denomination and had almost the same size and a design quite similar to the Argentine peso. The initial issue of Patacones were paid-off with interest in July 2002. At that time, about 2.65 billion pesos of new regional debt was issued with a maturity of November 13,2006 . Interestingly, the province announced that taxes could be paid with this debt, evidently at face value. In addition, the federal government issued 3.3 billion pesos of small denomination bonds called Lecops. Other provinces have also issued small denomination bonds. ${ }^{1}$ Ongoing negotiations with the IMF have focused on reductions in regional deficits and the termination of new issues of the small denomination regional debt. ${ }^{2}$

The need for some fiscal discipline binding national Treasuries in the EMU was recognized early on, leading to the various provisions of the Amsterdam Treaty limiting national deficits. However, it seems almost impossible to enforce these provisions. France and Germany, the two biggest economies of the EMU, breached the deficit ceilings in 2002, 2003 and plan to continue this conduct in 2004. But, on November 25, 2003, a majority of European Union's ministers of finance voted against sanctions imposed on these two countries. ${ }^{3}$ The issue now is how the European Central Bank will accommodate these rising deficits. The turmoil surrounding the Stability and Growth Pact of the EMU indicates that designing enforceable regulation of regional national public deficits and debts is not an easy matter.

These experiences in Argentina and Europe reflect the interplay between different government levels within a country. But these interactions are a more general phenomenon: they appear within any country with regional governmental levels, such as the states within the U.S., and in a monetary union, such as the EMU, in which fiscal policy is determined by individual countries. Thus, we are interested in addressing the following questions:

- Is the circulation of debt by a regional government equivalent to the creation of money by the central bank and thus inflationary?

- Or, does the issuance of such debt lead to future taxation without any money creation and thus without any inflation?

\footnotetext{
${ }^{1}$ To create some perspective, nominal GDP in Argentina in the fourth quarter of 2002 was 342 billion pesos and the money supply (M1) was 42 billion pesos in January 2003. We are extremely grateful to Maria Alzua for supplying us with these data about the regional debt and to George McCandless and Carlos Zarazaga for discussions on this experience. The money supply and nominal GDP figures are from http://www.mecon.gov.ar/progeco/dsbb.htm.

${ }^{2} \mathrm{An}$ IMF assessment of the situation in Argentina and proposed measures for reform are summarized at http://www.imf.org/external/np/sec/pr/2003/pr0309.htm.

${ }^{3}$ Financial Times, "EU sanctions deal leaves euro pact in tatters", November 252003.
} 
- What types of government interventions, such as limitations on regional debt, are required?

From a positive perspective, addressing the first two questions provides insight into the inflationary implications of regional debt, and answers the question posed in the title. The analysis also allows us to evaluate various forms of intervention which, as we shall see, may indeed be welfare improving. Our theory is therefore helpful in assessing the current fiscal situation in Argentina and the ongoing debate over the excessive deficits in countries belonging to the EMU.

We address these questions in an abstract monetary model of a federation sharing a common currency where one regional government issues bonds so as to make transfers to its citizens. We show the existence of two types of equilibria: one in which regional debt is backed by regional taxation and another in which regional debt is financed by an inflation tax. This multiplicity reflects a commitment problem of the central government. We thus argue that the inflationary effects of regional debt must be determined by the interactions of the market participants and cannot be ascertained a priori. From this perspective, policy interventions may be useful to coordinate on a socially preferred outcome.

In one equilibrium, which we term Ricardian, agents in a region who receive a transfer from their regional government save in anticipation of future taxes. As the regional debt is held largely by agents of that region in this kind of equilibrium, the central government will not bail-out the region but instead allow it to default. Anticipating this, the regional government will prefer to tax its own citizens to repay the debt. So the circulation of these regional bonds does not lead to any money creation.

In a second equilibrium, which we term Monetization, all agents union-wide anticipate a bail-out by the central government. Thus they all hold money and the debt issued by a region and, given this distribution of debt holdings, the central bank will choose to monetize the debt. Anticipating this, the regional government will not raise taxes to pay the debt but will choose to turn the obligation over to the central bank. ${ }^{4}$ Here the circulation of regional bonds is analogous to money creation by the central bank. This monetization of its debt will lead a region to run excessive deficits since the burden of the debt is shared by all regions.

The multiplicity of equilibria reflects a commitment problem by the central government vis-a-vis the regional government. If it were feasible, the central government would commit to never bailing out the regional government. Absent this ability to commit, the desire to equalize ex post per capita consumption across regions may lead the central government to bail-out a regional government.

A key distinguishing feature across the two equilibria is whether the debt is widely held in the economy or concentrated with agents in the bond-issuing region. In the former case, there is a bail-out as the central government will pay-off the regional debt. Knowing this, the regional government does not meet its obligation. In the latter case, the effects of the default are isolated as the agents in the bond-issuing region are, in effect, defaulting on themselves. Consequently, the central government will allow default rather than pay the obligation of the region. Anticipating this, the regional government will prefer to tax its citizens

\footnotetext{
${ }^{4}$ This theme of a region inducing monetization is present in related papers, including Aizenman (1992), Zarazaga (1995), Chari and Kehoe (1998), Chari and Kehoe (2002), Cooper and Kempf (2000) and Cooper and Kempf (2001). Here that argument is made in a setting with bonds and money. Further, those papers do not characterize the multiplicity of equilibria that may occur. Inman (2003) describes the reputational game between the central authority and sub-national units, highlighting the analogy of that game to the "Chain Store Paradox".
} 
and a Ricardian equilibrium arises. In all cases individuals are indifferent with regards to the composition of their portfolios: it is the aggregate distribution of holdings which is key to the equilibrium outcome.

To make the analysis transparent, the first section of the paper studies a real version of this problem. The second section studies these same themes in a monetary economy. This basic commitment problem facing the central policymaker emerges again though here we study the behavior of a central bank and its use of the inflation tax. We again find multiple equilibria which are differentiated by the holdings of regional debt. The more widely held the regional debt, the more likely is a bail-out by the central bank. Though it is not directly part of our analysis, it might be that small denomination debt, such as that issued by the province of Buenos Aires, is more likely to circulate throughout the economy, thus enhancing the possibility of a bail-out. In the fourth section, we offer a discussion of policy remedies for the socially excessive debt-financed regional spending in the Monetization equilibrium. Some interventions, such as limits on debt or even dollarization, may be socially desirable. The last section concludes. ${ }^{5}$

\section{A Real Game}

Consider a two-period economy composed of two regions, indexed $i=1,2$. There are $N_{i}$ agents in region $i$ and total population is given by $N=\sum N_{i}$. As the equilibria will depend on the fraction of agents in region 1 , we define $\Delta \equiv \frac{N_{1}}{N}$. Agents have endowments in youth and old age and have access to a storage technology.

For any individual in region $i$, the pair of consumption levels is denoted $\left(c_{i y}, c_{i o}\right)$. The lifetime utility function has the following form: $u\left(c_{i y}\right)+v\left(c_{i o}\right)$ and we assume that both $u(\cdot)$ and $v(\cdot)$ are strictly increasing and strictly concave.

Two levels of government are active: the government of region 1, denoted RG, and a central government, denoted CG. These governments have different objectives: the region 1 government is only concerned with the welfare of its citizens while the central government considers the welfare of all agents living in the federation. The RG makes a real transfer to region 1 agents in period 1 and can levy a lump-sum tax on region 1 agents in period 2. The CG makes no transfers and can levy a lump-sum tax on all agents in period 2 .

The game played by the CG and the RG is given in Figure 1. The timing of moves is the following:

- Period 1:

- Young agents in region 1 receive a real transfer, denoted $g^{1}$, from their government.

- Transfers to region 1 agents are financed by issuing regional debt, $B^{1}=N_{1} g^{1}$.

- All young agents make savings decisions in anticipation of period 2 government policies.

- Period 2:

- the region 1 government chooses to tax region 1 agents to finance its debt obligation or to pass the obligation to the central government.

\footnotetext{
${ }^{5}$ The discussion of dollarization draws upon Cooper and Kempf (2001) and the arguments for constraints are related to the points made in Chari and Kehoe (2002) and Cooper and Kempf (2000).
} 
- if the region 1 government does not levy the tax, then the central government can choose to levy an economy-wide tax to finance the debt obligation of region 1.

- if the central government decides not to levy this tax, then region 1 automatically defaults on its debt and region 1 agents bear a default cost, denoted $\kappa .^{6}$

Figure 1 Here

We search for sub-game perfect Nash equilibria of this game. Accordingly, the central government is restricted to choices which are credible. Put differently, the central government may threaten not to bailout a regional government but these threats have an influence on the equilibrium outcome only if they are credible.

Before proceeding, it is useful to characterize the planner's solution as a benchmark. Assume that the planner chooses an allocation of consumption goods over time and over regions at the start of time given the endowments of agents in each period, and given a technology that creates $x$ units of period 2 goods per unit stored in period 1 . Let the objective function of the planner be the population weighted average of the lifetime utilities of individual agents, $\Delta\left(u\left(c^{y 1}\right)+v\left(c^{o 1}\right)\right)+(1-\Delta)\left(u\left(c^{y 2}\right)+v\left(c^{o 2}\right)\right)$, where $c^{y i}$ and $c^{o i}$ are the consumption levels of a young agent in region $i$ in youth and old-age, respectively. Then the solution is to equalize consumption of agents across regions and the optimal consumption profile $\left(c^{y *}, c^{o *}\right)$ satisfies the Euler equation $u^{\prime}\left(c^{y *}\right)=x v^{\prime}\left(c^{o *}\right)$.

We term this the commitment solution as it corresponds to the outcome if the central government could commit, at the start of period 1 before young agents make their saving decision, not to levy an economy-wide tax to bail-out the regional government. Of course, in the extensive form game outlined above, the central government does not have this commitment ability. We now turn to an analysis of the equilibria for the game without commitment. ${ }^{7}$

\subsection{Period 1 Optimization}

Region $i$ young agents solve

$$
\max _{s^{i}} u\left(\omega^{y}+g^{i}-s^{i}\right)+v\left(\omega^{o}+s^{i} x-\tau-\tau^{i}\right)
$$

where $s^{i}$ is real savings, $g^{i}$ is a real transfer in youth per capita in region $i, \omega^{y}$ is the endowment in youth, $\omega^{o}$ is the endowment in old age, $\tau$ is a common tax and $\tau^{i}$ is the regional tax. Savings takes two forms: storage $\left(k^{i}\right)$ and the holding of region 1 debt $\left(b^{i}\right)$. The return on storage is given by $x$ and, in equilibrium, this is the return on regional debt as well. Assume that the only action is in region 1 so that $g^{2} \equiv \tau^{2} \equiv 0$.

The first-order condition for this problem is

\footnotetext{
${ }^{6}$ Though there is a default cost, we have no theory about the implications of default. Thus the default cost plays a very modest role: we assume that $\kappa$ is negligible and use it solely to "break ties".

${ }^{7}$ Thus the problem falls within the general class of team incentive problems where the central government is the principal and the regional governments are the agents. The structure of the problem is thus similar to the family incentive problem and the infamous "Rotten Kid Theorem" as formalized in Bergstrom (1989) and extended in Lindbeck and Weibull (1988) and Bruce and Waldman (1990).
} 


$$
u^{\prime}\left(c^{y i}\right)=x v^{\prime}\left(c^{o i}\right)
$$

for $i=1,2$. The savings decision will depend, in part, on the taxes that young agents anticipate in period 2. Nonetheless, it is straightforward to see that as $u(c)$ is strictly concave, $s^{1}>s^{2} .8$

The composition of saving though is indeterminate as government debt must offer the same return as storage for an equilibrium in which debt is held to exist. Still it is important for characterizing the set of equilibria to keep track of the distribution of debt holdings.

Denote the per-capita saving of region $i$ and its composition by $s^{i}=k^{i}+b^{i}$. Let $\theta=\frac{N_{1} b^{1}}{B^{1}}=\frac{\Delta b^{1}}{\bar{B}}$ where $\bar{B} \equiv \frac{B^{1}}{N}$ is the level of region 1 debt divided by total population. By symmetry, $(1-\theta)=\frac{(1-\Delta) b^{2}}{\bar{B}}$.

\subsection{Bail-out Equilibrium}

In a bail-out equilibrium, $\tau^{1}=0$ and $\tau=\Delta g^{1} x=\bar{B} x$. Savings by the two regions are given by the first-order conditions anticipating this common tax. We show there is a continuum of bail-out equilibria, indexed by the share of the debt held by agents in region $1 .{ }^{9}$

Proposition 1 There exists a bail-out equilibrium for $\theta \in[0, \Delta]$.

\section{Proof.}

To characterize the set of bail-out equilibria, we first check the incentives of the central government assuming the regional government has decided not to tax its citizens. We then check the incentives of the regional government and the private agents in turn.

For the CG, let $W^{b}$ and $W^{d}$ denote social welfare under a bail-out and a default respectively. In a bail-out equilibrium, the consumption of an old region $i$ agent is $c^{o i}=\omega^{o}+s^{i} x-\tau$ where the tax satisfies $\tau=\bar{B} x$. Thus, $W^{b}$ is:

$$
W^{b}=\Delta v\left(\omega^{o}+s^{1} x-\bar{B} x\right)+(1-\Delta) v\left(\omega^{o}+s^{2} x-\bar{B} x\right)
$$

Under a default, consumption is given by $\tilde{c}^{o i}=\omega^{0}+k^{i} x$. Using $s^{i}=b^{i}+k^{i}$ and the definition of $\theta$, social welfare under a default is:

$$
W^{d}=\Delta v\left(\omega^{o}+\left(s^{1}-\frac{\theta \bar{B}}{\Delta}\right) x\right)+(1-\Delta) v\left(\omega^{o}+\left(s^{2}-\frac{(1-\theta) \bar{B}}{(1-\Delta)}\right) x\right)
$$

If $\theta=\Delta, W^{b}=W^{d}$. With a negligible value of $\kappa$, the CG will choose bail-out over default.

Next, we establish that $k^{1}>k^{2}$ for any $\theta \leq \Delta$. At $\theta=\Delta, b^{1}=b^{2}$ so that $s^{1}>s^{2}$ implies $k^{1}>k^{2}$. As $\theta$ decreases, $b^{1}$ falls relative to $b^{2}$ and so $k^{1}$ increases relative to $k^{2}$ since $s^{1}$ and $s^{2}$, given by (2), are independent of $\theta$. Hence, $k^{1}>k^{2}$ for any $\theta \leq \Delta$. Consequently, the derivative of $W^{d}$ with respect to $\theta$, given by $-\left[v^{\prime}\left(\omega^{o}+k^{1} x\right)-v^{\prime}\left(\omega^{o}+k^{2} x\right)\right] \bar{B} x$, is positive when $\theta \leq \Delta$.

\footnotetext{
${ }^{8}$ This reflects two features of the problem: $g^{1}>g^{2}=0$ and $\tau^{1} \geq \tau^{2}=0$. The result that $s^{1}>s^{2}$ then follows from (2) as $u(c)$ is strictly concave.

${ }^{9}$ We are grateful to Marco Bassetto for discussions which led to the enhanced development of this section relative to an earlier draft.
} 
So, $W^{b}=W^{d}$ when $\theta=\Delta$ implies $W^{b}>W^{d}$ for $\theta<\Delta$. This implies that the CG will bail-out the regional government for $\theta \leq \Delta$.

Anticipating this, the region 1 government will always choose not to tax for $\theta \leq \Delta$. If it did levy a tax $\tau^{1}$, the consumption of region 1 old agents would be $\hat{c}^{o 1}=\omega^{o}+\left(s^{1}-\frac{\bar{B}}{\Delta}\right) x$ since $\tau^{1}=\frac{\bar{B}}{\Delta} x=g^{1} x .^{10}$ With $\Delta<1, c^{o 1}>\hat{c}^{o 1}$ so that the regional government prefers not to tax its citizens.

In anticipation of these choices by the governments, private agents' savings decisions satisfy (2) under the expectation of $\tau_{1}=0$ and $\tau=\bar{B} x$. Thus there exists a bail-out equilibrium for $\theta \leq \Delta$.

The proof rests upon the basic intuition associated with the ex post incentive of the central government to redistribute resources towards a more equal allocation. For $\theta \leq \Delta$, consumption levels are more equal across regions under a bail-out than under a default. Consequently, the CG is unable to commit not to redistribute resources. The regional government recognizes this and chooses not to tax it citizens.

There is a subtle point here. Total consumption in the second period is fixed, given endowments and storage decisions. So, the redistribution by the CG increases the consumption of region 2 agents and reduces the consumption of region 1 agents relative to the default allocation. Thus the redistribution per se is not favorable to region 1 agents. Still, their consumption is higher under a bail-out than if they paid the entire tax bill. Put differently, the analysis above shows $\tilde{c}^{o 1} \geq c^{o 1}>\hat{c}^{o 1} \cdot{ }^{11}$ The first inequality indicates the lost consumption of redistribution and the second inequality indicates that consumption is higher under a bail-out than regional taxation. In effect, the region 1 agents are able to take advantage of the desires of the CG to redistribute consumption away from them.

Figure 2 Here

This is illustrated in Figure 2 which indicates the consumption levels of the old agents in both regions under different allocations. This graph takes as given the savings decisions of the agents and thus total resources available for consumption are fixed, as indicated by the negatively sloped resource constraint. The allocation under a bail-out is labelled $B$, the allocation under default is labelled $D$ and the one under regional taxation is labelled $R$. As seen in this figure, the bail-out of the CG redistributes from region 1 to region 2 agents relative to the default allocation. Still this allocation is preferred by region 1 to the one achievable with regional taxation.

\subsection{A Ricardian Equilibrium}

In this section we construct a Ricardian equilibrium in which the regional government uses its tax to payoff the debt issued to finance the transfer, $g^{1}$. Thus $\tau^{1}=x g^{1}$ and $\tau=0$ along the equilibrium path. In equilibrium, the region 1 agents will save the transfer to pay for their future taxes: $s^{1}=s^{2}+g^{1}$. This condition relating $s^{1}$ to $s^{2}$ is an immediate consequence of (2) under the expectation of a Ricardian equilibrium.

Proposition 2 There exists a Ricardian equilibrium for $\theta=1$.

\footnotetext{
${ }^{10}$ Since this defection of the regional government arises in period 2 , the level of region 1 saving is the same as it is along the equilibrium path. It follows that $\hat{c}^{01}<\hat{c}^{02}$ since $0<s^{1}-s^{2}<g^{1}$.

${ }^{11}$ If $\theta<\Delta$, then $\tilde{c}^{o 1}>c^{o 1}$. This implies that points $\mathrm{B}$ and $\mathrm{D}$ are distinct in the figure below.
} 
Proof. To construct this equilibrium, we assume that only region 1 agents choose to hold region 1 debt. That is, in the proposed equilibrium, $s^{2}=k^{2}$ so that $s^{1}=s^{2}+b^{1}$. Hence $\theta=1$. At the individual level, this is without loss of generality as debt and storage have the same return of $x$. Given this conjectured equilibrium, we check the incentives of the central and regional governments as well as the private agents.

Since the CG moves last, we check its incentives first. If the regional government deviates from the candidate equilibrium and chooses not to raise taxes to pay the debt obligation, will the CG allow default? Let $W^{b}$ again denote social welfare if the central government bails-out the region:

$$
W^{b}=\Delta v\left(\omega^{o}+s^{1} x-\tau\right)+(1-\Delta) v\left(\omega^{o}+s^{2} x-\tau\right)
$$

From the curvature in $v(\cdot)$, using $s^{1}=s^{2}+g^{1}$, and setting $\tau=\Delta g^{1} x$ from the CG's budget constraint,

$$
W^{b}<v\left(\omega^{o}+\left(\Delta s^{1}+(1-\Delta) s^{2}\right) x-\tau\right)=v\left(\omega^{o}+s^{2} x\right)
$$

If the central government allows default then social welfare, denoted $W^{d}$, is given by

$$
W^{d}=\Delta v\left(\omega^{o}+\left(s^{1}-g^{1}\right) x\right)+(1-\Delta) v\left(\omega^{o}+s^{2} x\right)=v\left(\omega^{o}+s^{2} x\right)
$$

where the last equality again uses $s^{1}=s^{2}+g^{1} \cdot{ }^{12}$ In $(7)$, the consumption of region 1 agents reflects the default on the debt they hold and the absence of taxation. Hence, from (6) and (7), $W^{d}>W^{b}$.

Anticipating that the central government will not bail-out, the regional government can choose to tax its own citizens or allow a default. If region 1 levies a tax, the consumption of its citizens is $\hat{c}^{o 1}=\omega^{o}+\left(s^{1}-g^{1}\right) x$, exactly the same consumption that occurs under a default. With a negligible $\kappa$ the regional government will prefer to tax its citizens.

Finally, from (2), it is easy to check that region 1 agents will simply save the entire transfer in order to pay their tax obligations to the regional government: i.e. $s^{1}=s^{2}+g^{1}$. Given the construction that only region 1 agents hold region 1 debt, all agents have the same real storage: i.e. $s^{1}=s^{2}+g^{1}$ and $s^{2}=k^{2}$ imply $k^{1}=k^{2}$.

So private agents are optimizing and neither the regional nor the central government has an incentive to deviate. Hence there is an equilibrium in which regional debt is paid-off by regional taxation.

It is important to understand more intuitively this equilibrium. From (6) and (7), the central government is interested in the ex post distribution of consumption across agents in the different regions. Since $v(\cdot)$ is strictly concave, the CG prefers a more equitable allocation. The result that $W^{d}>W^{b}$ reflects the fact that default delivers more equitable consumption across the regions than would a bail-out.

Note too that this is an isolated equilibrium. That is, for $\theta<1$, there will not exist a Ricardian equilibrium. When $\theta<1$, the regional government will no longer be indifferent between taxing its citizen and allowing the CG to default. Instead it will strictly prefer default since, with $\theta<1$ some of its tax revenues will flow to region 2 agents. ${ }^{13}$

\footnotetext{
${ }^{12}$ As noted earlier, we are setting the default cost at 0 and using it only to break ties. Thus $\kappa$ is not in $W^{d}$.

${ }^{13}$ However, with $\kappa>0$ it is possible to support other Ricardian equilibria.
} 


\section{A Monetary Economy with Regional Debt}

This analysis of the real game serves two purposes. First, it highlights the commitment problem of the central authority within a federation. Second, it indicates that a central government will ex post use its tax and transfer power to redistribute resources across regions. This incentive will be relevant even in a monetary economy.

Yet the discussion of regional debt occurs in a monetary setting where the connection between regional debt and inflation arises from the use of the inflation tax by a central government. Thus understanding the interactions between the regional and central government in a monetary setting is important. Here we construct an overlapping generations model. Instead of assuming there exists a central government which can tax all agents, there is a central bank $(\mathrm{CB})$ which can print money and transfer it to the regional government to pay its obligations. In the overlapping generations model, agents live for two periods. Lifetime utility is given by $u\left(c^{y}\right)+v\left(c^{o}\right)$ and we assume that $u(\cdot)$ and $v(\cdot)$ are strictly increasing and strictly concave. All agents are endowed with $\omega^{y}$ units of the consumption good in youth and $\omega^{o}$ in old age. Agents have access to a storage technology that yields $x>1$ units of the consumption good in period $t+1$ for each unit stored in period $t$. In addition, agents may save by holding debt issued by the region 1 government. Finally, there is a legal restriction that requires money to be held in proportion to the level of real storage, as in Smith (1994). One interpretation is that access to the storage technology requires an intermediary which must hold money as a reserve requirement. ${ }^{14}$

Agents live in one of two regions. As in the previous section, the key is the game between the region 1 government and the central bank (CB). There is a second group of agents living in region 2, whose government does not issue debt. ${ }^{15}$ Nonetheless region 2 agents are important as their welfare is reflected in the decisions of the CB. Each young agent of generation $t$ born in region 1 receives a real transfer of $g^{*}$ from the regional government and that government sells debt of $B^{*}{ }^{16}$ Governments are associated with a generation not a time period; the regional government elected in period $t$ sells its debt and then in period $t+1$ decides either to tax the consumption of the old within its region or to turn the obligation over to the CB. ${ }^{17}$

Formally, we consider a extensive form game, played each period, which is similar to that in the previous section. Here though the move of the central government has been replaced by a choice of the central bank.

- regional government either raises taxes to pay its obligation (pay) or not (no pay) and passes it to the $\mathrm{CB}$

- if the regional government chooses (no pay), the CB either pays the obligation, financed by printing

\footnotetext{
${ }^{14}$ We are grateful to Todd Keister for discussions on this point. Alternatively, we could assume there is a reserve requirement on all savings, including the holding of government debt. If we assume that the regional bond has a small nominal value, as is the cases with patacones, there is no need for it to be intermediated and thus no basis for a reserve requirement.

${ }^{15}$ In the context of Argentina, region 1 is intended to represent the province of Buenos Aires and region 2 representing the citizens outside of this region. This simplification clearly misses the fact that other regions have also issued small denomination debt. But the province of Buenos Aires accounts for about $60 \%$ of the regional debt outstanding.

${ }^{16}$ Hereafter, variables with an ${ }^{*}$ are steady state equilibrium values.

${ }^{17}$ In fact, this is apparently without loss of generality since a regional government in period $t$ has no influence over any state variables that matter for future generations.
} 
money, or denies it

- if the $\mathrm{CB}$ denies the obligation, then the region defaults and its citizens suffer a default cost of $\kappa$.

This game is played in period $t+1$ by the regional government representing region 1 , generation $t$ agents. Importantly, the taxation decisions associated with generation $t$ agents are made in period $t+1$ after savings decisions have been made by that generation.

We construct two types of steady states for this economy. In the first, which is an extension of the bail-out equilibrium, the CB monetizes the debt of the regional government. In the second, akin to the Ricardian outcome, the CB refuses to monetize and, in anticipation, the regional government taxes its citizens.

The co-existence of these equilibria again reflects the commitment problem faced by the CB, as in the real game. In the extensive form game, the CB has the weighted utilities of all old agents as its objective. Accordingly, it is ultimately interested in equalizing the real consumptions of these agents. Whether or not it allows default on the debt depends on the holdings of this debt across agents. In the monetization equilibrium, the debt is widely held and allowing default is undesirable due to the default cost. But, if the debt is held by region 1 agents, then default by the CB leads to more equitable consumption. This supports a decision to tax by the regional government and thus a Ricardian equilibrium.

Thus which equilibrium will prevail depends on who holds the regional debt. Since, in equilibrium, agents get the same return from holding the regional debt as from storage (i.e. default never actually occurs in equilibrium), agents are indifferent with respect to their portfolios. ${ }^{18}$ Despite this indifference at the level of the individual, the outcomes in the two equilibria may be quite different.

\subsection{Equilibrium with Monetization}

Here we construct a stationary equilibrium in which the CB monetizes the obligation rather than allowing default. The agents anticipate this and adjust their saving accordingly. Further, the region chooses no pay and sends the obligation to the CB. In equilibrium, the CB prefers monetization over default. There is an interpretation of the patacones in this equilibrium. Their creation is ultimately inflationary as the CB is unable to stop itself from monetizing the regional debt.

Along the equilibrium path, each region 1 government transfers $g^{*}$ to each young agent of region 1 . These transfers are financed by issuing one-period debt each period of $B^{*}$ per capita. ${ }^{19}$ By the regional government's budget constraint, $B^{*}=\Delta g^{*}$ where $\Delta$ is the population size of region 1 .

We begin with the optimization problem of a representative young agent in region $i$, period t. That agent solves

$$
\max _{k^{i}, b^{i}, m^{i}} u\left(\omega^{y}+g^{i}-k^{i}-b^{i}-m^{i}\right)+v\left(\omega^{o}+k^{i} x+b^{i} R+m^{i} \tilde{\pi}\right)
$$

where $g^{i}$ is the real transfer to each region 1 young agent. There are three types of savings: $k^{i}$ is real storage with return $x, b^{i}$ is the holding of real debt with a real return of $R$ and $m^{i}$ is the holding of real money. We impose a legal restriction, $m^{i} \geq \lambda k^{i}$, to generate a demand for money. The real return on the

\footnotetext{
${ }^{18}$ Interestingly, the Patacones have traded at less than face value perhaps indicating that private agents place positive probability on default.

${ }^{19}$ So here these variables are divided by total population, normalized at 1 , and not region 1 population.
} 
holding of money, $\tilde{\pi}$, is the inverse of (one plus) the inflation rate. Along the equilibrium path, the inflation is anticipated by young agents.

Since the return on holding of money will, in equilibrium, be less than the return on storage, the reserve requirement will bind: $m^{i}=\lambda k^{i}$. Thus the return on storage, given the reserve requirement, is $\frac{x+\lambda \tilde{\pi}}{1+\lambda}$ per unit placed in storage. ${ }^{20}$ In equilibrium, this must be the same as the return on regional debt, $R$.

With this in mind, the optimization problem simplifies to

$$
\max _{s} u\left(\omega^{y}+g^{i}-s^{i}\right)+v\left(\omega^{o}+s^{i} R\right)
$$

where $s^{i} \equiv k^{i}(1+\lambda)+b^{i}$ represents total saving and $R=\frac{x+\lambda \tilde{\pi}}{1+\lambda}$. The optimal savings decision, which depends on $R$, is denoted by $s^{i *}(R)$, and satisfies

$$
u^{\prime}\left(\omega^{y}+g^{i}-s^{i *}\right)=R v^{\prime}\left(\omega^{o}+s^{i *} R\right)
$$

for $i=1,2$.

Since only region 1 has transfers, set $g^{1}>0$ and $g^{2}=0$. This implies that $s^{1 *}>s^{2 *}$. If, to the contrary, $s^{1 *} \leq s^{2 *}$, then the left-side of (10) would be lower for region 1 agents and the right-side would be higher. This would violate (10). We assume throughout that $s^{i}$ is strictly positive, i.e. $w^{y}$ is sufficiently large relative to $w^{o}$. Further, in the equilibria we construct, the constraint that $k^{i} \geq 0$ does not bind, i.e. $B^{*}$ is not too large. The rate of inflation is determined from market clearing and the activity of the central bank. Monetization of the debt $B^{*}$ by the central bank implies

$$
\frac{M^{\prime}-M}{p^{\prime}}=R B^{*} .
$$

Here unprimed variables are current ones and primed ones are future variables. So, for any generation, $M$ is the current money supply and $M^{\prime}$ is the future stock of money. Likewise, $p$ is the current prices of goods in terms of money and $p^{\prime}$ is the future price. ${ }^{21}$

A monetary equilibrium requires that the supply of real money balances (by both old agents and the CB) equals the demand by the young who have to meet their reserve requirement. So market clearing implies

$$
\frac{M}{p}=\lambda \bar{k}^{*}(R) .
$$

Here $\bar{k}^{*}(R) \equiv \Delta k^{* 1}(R)+(1-\Delta) k^{* 2}(R)$ and represents total storage. Using (12) in (11) yields

$$
\frac{M^{\prime}}{p^{\prime}}-\frac{M}{p} \frac{p}{p^{\prime}}=\lambda \bar{k}^{*}(R)(1-\tilde{\pi})=R B^{*}
$$

where $\tilde{\pi}=\frac{p}{p^{\prime}}$.

These conditions for market clearing, along with the choices of young agents will characterize a steady state equilibrium with monetization. This equilibrium is comprised of a vector of choices by agents in each region and a rate of return on money: $\left(k^{1 *}, s^{1 *}, k^{2 *}, s^{2 *}, \tilde{\pi}^{*}\right)$. Along the equilibrium path, given the constant level of government debt $B^{*}$, there will be constant growth of the money supply, constant inflation and thus

\footnotetext{
${ }^{20}$ Put differently, it costs $1+\lambda$ units of consumption today to get $x+\lambda \tilde{\pi}$ units of consumption tomorrow. Hence the return per unit stored is the ratio.

${ }^{21} \mathrm{As}$ we focus on steady states, we have ignored all the $t$ subscripts.
} 
a constant real return on money, $\tilde{\pi}^{*}$. This gets factored into the return on savings so that $R^{*}=\frac{x+\lambda \tilde{\pi}^{*}}{1+\lambda}$ is the return on savings along the equilibrium path and determines $s^{i *}$. As storage and regional debt have the same return, we can freely construct agents' portfolios as part of the equilibrium. We focus on steady state equilibria where all young agents of region 1 holds a fraction $\theta$ of the outstanding debt: $b^{1 *}=\frac{\theta B^{*}}{\Delta}$.

In characterizing the individual decisions and market clearing, we have assumed an equilibrium with $\mathrm{CB}$ monetization. There are no regional taxes assumed in (10) and all financing was through money creation, as in (11). We need to check that this is an equilibrium by evaluating the incentives of the regional government and the central bank. The following intuition underlies the proof of Proposition 3.

First, consider the incentives of the CB. Its choice about monetizing the regional debt influences the current nominal money supply and thus may redistribute purchasing power across old agents. But this choice has no effect on future generations since the inherited stock of fiat money is completely neutral. ${ }^{22}$ So the CB looks only at the welfare of the current old. If it bails-out, then social welfare, $W^{b}$, is given by

$$
W^{b}=\Delta v\left(\omega^{o}+R^{*} s^{1 *}\right)+(1-\Delta) v\left(\omega^{o}+R^{*} s^{2 *}\right)
$$

in the steady state. If the CB allows default, then the welfare of the current old is given by

$$
W^{d}=\Delta v\left(\omega^{o}+k^{1 *}(x+\lambda)\right)+(1-\Delta) v\left(\omega^{o}+k^{2 *}(x+\lambda)\right)
$$

since, under default, there is no return on the holding of government debt and no inflation for this generation of old agents. ${ }^{23}$

To compare $W^{d}$ against $W^{b}$ we have to compare the ex post consumption levels. As argued in the proof of Proposition 3, the consumption allocation under bail-out is closer to the social optimum of equal consumption and hence $W^{b}>W^{d}$. Finally, we need to be sure that the region will pass the obligation to the $\mathrm{CB}$ given that it recognizes the $\mathrm{CB}$ will choose to monetize, i.e. $W^{b}>W^{d}$. Again this is intuitive: why pay a tax which can in part be passed to other agents? This is formalized in the proof of Proposition 3.

Proposition 3 For $\theta \leq \Delta$, there exists a steady state for a given of level of region 1 debt, $B^{*}$, in which the central bank monetizes the regional debt obligation.

Proof. First, we argue that there exists a $\left(k^{1 *}, s^{1 *}, k^{2 *}, s^{2 *}, \tilde{\pi}^{*}\right)$ which solves the conditions for a stationary monetary equilibrium. Second, we check the incentives of the regional and central governments.

The existence proof relies on two equilibrium conditions: (13) and $R(\tilde{\pi})=\frac{x+\lambda \tilde{\pi}}{1+\lambda}$. Substitution of $R(\tilde{\pi})$ into (13) yields:

$$
\lambda \bar{k}(\tilde{\pi})(1-\tilde{\pi})=B^{*}\left[\frac{x+\lambda \tilde{\pi}}{1+\lambda}\right] .
$$

Here $\bar{k}(\tilde{\pi})$ reflects the dependence of aggregate savings and thus aggregate storage (given $B^{*}$ ) on $R(\tilde{\pi}$ ). Denote the left-side of $(16)$ by $H(\tilde{\pi})$ and the right-side by $G(\tilde{\pi})$. Clearly $G(\tilde{\pi})$ is linear with a positive intercept. With $B^{*} \geq 0, \tilde{\pi} \in[0,1]$ from (13). $H(1)=0$ and thus $H(1)<G(1)$. Since both functions are continuous, if $H(0)>G(0)$, there will exist a $\pi$ which solves (16). We assume endowments such that there

\footnotetext{
${ }^{22}$ So while the stock of fiat money is changing over time, it has no influence on the set of feasible consumption allocations.

${ }^{23}$ Importantly, we are considering a one-time deviation from a candidate equilibrium. As before, the default cost is assumed to be negligible and is not included in $W^{d}$.
} 
is positive saving at $\tilde{\pi}=0$. Hence for $B^{*}$ sufficiently low, $H(0)>G(0)$ and so there will exist a $\tilde{\pi}$, denoted $\tilde{\pi}^{*}$, solving (16). Given $\tilde{\pi}^{*}, R^{*}$ is determined and thus so are total saving and storage. This proof holds for $\theta \leq \Delta$

To see the incentive of the $\mathrm{CB}$ to monetize use (13) and $b^{1 *}=B^{*} \frac{\theta}{\Delta}$ to write the consumption of old agents under monetization as

$$
\begin{gathered}
c^{o 1 *}=\omega^{o}+b^{1 *} R^{*}+k^{1 *}\left(x+\lambda \tilde{\pi}^{*}\right)=\omega^{o}+k^{1 *}(x+\lambda)+R^{*} B^{*}\left(\frac{\theta}{\Delta}-\frac{k^{1 *}}{\bar{k}^{*}}\right) \\
c^{o 2 *}=\omega^{o}+b^{2 *} R^{*}+{ }^{2 *}\left(x+\lambda \tilde{\pi}^{*}\right)=\omega^{o}+k^{2 *}(x+\lambda)+R^{*} B^{*}\left(\frac{(1-\theta)}{(1-\Delta)}-\frac{k^{2 *}}{\bar{k}^{*}}\right)
\end{gathered}
$$

Write the consumption of old agents in region $i$ under default as

$$
\tilde{c}^{o i}=\omega^{o}+k^{i *}(x+\lambda) .
$$

From these expressions, total consumption available to all agents in a given period is independent of whether the $\mathrm{CB}$ choses to bail-out the region or allow a default. That is, $\Delta c^{o 1}+(1-\Delta) c^{o 2}=\omega^{o}+k^{i *}(x+\lambda)$ under both default and bail-out. Thus, if consumption allocations under the bail-out were more equal than they are under default, (assuming that in both cases region 1 old agents had higher consumption), then the CB would choose bail-out.

Recall that $s^{i}=k^{i}(1+\lambda)+b^{i}$. Since $s^{* 1}>s^{* 2}$ holds by (10) for any $\theta$, and $b^{1} \leq b^{2}$ for $\theta \leq \Delta$, it follows that $k^{1 *}>\bar{k}^{*}>k^{2 *}$ for $\theta \leq \Delta$. Further, the consumption of region 1 agents exceeds that of region 2 agents in the monetization equilibrium since $s^{* 1}>s^{* 2}$. So, inflation redistributes consumption from region 1 to region 2 agents, (but does not eliminate the advantage in region 1 consumption). Thus, relative to the allocation under default, consumption is more equal under monetization. From the strict concavity of $v(\cdot)$, $W^{b}>W^{d}$ and the CB will prefer to monetize rather than allow default.

Finally, we inspect the incentives of the region 1 government. Let $\hat{c}^{o 1}$ denote the consumption of region 1 agents in the event that the region 1 government taxes the consumption of these agents at a rate of $\tau^{1}$. From the budget constraint of the regional 1 government, $\Delta \tau^{1}=B^{*} R^{*}$. Using this constraint to determine taxes,

$$
\hat{c}^{o 1}=\omega^{o}+k^{1 *}(x+\lambda)+\frac{B^{*} R^{*}}{\Delta}(\theta-1) .
$$

Note that in this expression the savings choices of the private agents are $\left(k^{1 *}, b^{1 *}\right)$ since this proposed deviation from the equilibrium occurs after private agents choose their savings.

There are two differences between this and old consumption in the steady state, given in (17). First, the inflation is zero and second there is a tax to be paid. The difference between $c^{o 1 *}$ and $\hat{c}^{o 1}$ is

$$
B^{*} R^{*}\left[\frac{1}{\Delta}-\frac{k^{1 *}}{\bar{k}^{*}}\right]=\frac{B^{*} R^{*}}{\Delta \bar{k}^{*}}\left(\bar{k}^{*}-\Delta k^{1 *}\right)>0
$$

Thus the regional government prefers to allow the CB to monetize the debt rather than tax its agents directly.

This result indicates the obligations of the regional government will be assumed by the CB. As a consequence, the regional transfers are financed by an economy-wide inflation tax, partially borne by agents in region 2 . 
As in the real game, the redistribution in the bail-out is from agents in region 1 to those in region 2 . With $\theta \leq \Delta$, the young of region 1 have more storage and thus hold more money. As a consequence, the region 1 agents bear more of the inflation tax. Still, the bail-out is preferred to payment of taxes by region 1 agents.

\subsection{Ricardian Equilibrium}

Here we characterize a second equilibrium in which the regional government prefers to tax its agents. In this equilibrium the $\mathrm{CB}$, given the opportunity to act, would not choose to monetize. Rather it would allow default. In anticipation of this, the region will tax. Given this, the agents in region 1 save more and thus pay taxes from this extra savings. In the equilibrium this extra savings is in the form of holding of debt. Therefore only region 1 agents hold the debt. This concentrated holding of debt is essential for the construction of the Ricardian equilibrium. It makes clear how the distribution of debt holdings matters for the equilibrium outcome.

In this Ricardian equilibrium, assets like the Patacones issued by the regional government in Argentina are not money in the traditional sense as their creation is not associated with increases in prices. Instead, they simply represent debt, backed by future taxes. ${ }^{24}$

To characterize this outcome we return to the basic optimization problems and equilibrium conditions. The representative young agent in region $i$, period $t$ solves

$$
\max _{s} u\left(\omega^{y}+g^{i}-s^{i}\right)+v\left(\omega^{o}+s^{i} R-\tau^{i}\right) .
$$

This optimization yields

$$
u^{\prime}\left(\omega^{y}+g^{i}-s^{* i}\right)=R v^{\prime}\left(\omega^{o}+s^{* i} R-\tau^{i}\right)
$$

where $\tau^{2}=g^{2} \equiv 0$. Along this equilibrium path there will be no inflation so $R=\frac{x+\lambda}{1+\lambda}$.

In the construction of this equilibrium, we assume that only region 1 agents hold regional debt: $b^{1 *}=$ $B^{*} / \Delta, b^{2 *}=0$. Further, we conjecture (and prove in Proposition 4) that $s^{1 *}=s^{2 *}+b^{1 *}$ so that $k^{1 *}=k^{2 *}$.

There is a money market clearing condition that is analogous to (12). This condition will determine the price level given the fixed money supply and the storage decisions of the agents.

To argue that there is an equilibrium with regional taxation and no monetization by the $\mathrm{CB}$, we need to check the incentives for the levels of the government and private agents. This is done formally in Proposition 4; we bring out the intuition here.

We start in the sub-game where the regional government has decided not to tax and the CB must choose to monetize the debt or allow default. This is a deviation from the equilibrium we are trying to construct. Social welfare under a CB bail-out is

$$
W^{b}=\Delta v\left(\omega^{o}+k^{1 *}(x+\lambda \tilde{\pi})+b^{1 *} R\right)+(1-\Delta) v\left(\omega^{o}+k^{2 *}(x+\lambda \tilde{\pi})\right)
$$

\footnotetext{
${ }^{24}$ In the model there is no rollover option. But, if this were possible, then with a limit on debt issues the game we outline between the regional government and the central bank will ultimately occur.
} 
where $\left(k^{i *}, b^{i *}\right)$ are obtained from optimal savings along an equilibrium path from (23). ${ }^{25}$ Here $\tilde{\pi}$ is again the inverse of the inflation rate and inflation is caused by the monetization of the debt by the $\mathrm{CB}$. If the central bank does not bail-out and there is a default, then social welfare is given by

$$
W^{d}=\Delta v\left(\omega^{o}+k^{* 1}(x+\lambda)\right)+(1-\Delta) v\left(\omega^{o}+k^{* 2}(x+\lambda)\right)
$$

so agents avoid the inflation tax but only get a return on their storage and money holdings.

The proof of Proposition 4 shows that $W^{d}>W^{b}$. This reflects two factors which were present in the proof of Proposition 3 as well. First, the actual resources available to distribute to the old agents is the same regardless of the action of the central bank. Second, the central bank wishes to obtain the most equitable distribution of consumption across the old agents since $v(\cdot)$ is strictly concave. This is achieved under default given that $k^{1 *}=k^{2 *}$.

Anticipating this, region 1 will prefer to raise taxes rather than allowing default. Interestingly, in both cases, the consumption of region 1 old agents is the same. Intuitively, the taxes they pay to the regional government are just used to pay-off the debt which they hold. But, by taxing, the regional government can avoid the infinitesimal default cost.

Proposition 4 There exists a steady state equilibrium given $B^{*}$ in which the regional debt is held only by region 1 agents and the regional government chooses to raise taxes to pay its obligations.

Proof. First, we argue that there exists a $\left(k^{1 *}, s^{1 *}, k^{2 *}, s^{2 *}, \tilde{\pi}^{*}\right)$ which satisfies the conditions for a stationary monetary equilibrium. Second, we check the incentives of the regional and central governments.

In the steady state, the level of region 1 transfers to each young agent is $g^{*}$, the total per capita debt outstanding is $B^{*}$. By the budget constraint of region $1, B^{*}=\Delta g^{*}$ and taxes in old age are given by $\Delta \tau^{1}=R^{*} B^{*}$ so that $\tau^{1}=R^{*} g^{*}$. The debt held by each agent in region 1 is $b^{1 *}$ where $\Delta b^{1 *}=B^{*}$ and region 2 agents do not hold any debt.

In equilibrium, the saving decisions of the agents are given by

$$
u^{\prime}\left(\omega^{y}+g^{i}-k^{i *}(1+\lambda)-b^{i *}\right)=R^{*} v^{\prime}\left(\omega^{o}+k^{i *}(x+\lambda)+R^{*} b^{i *}-\tau^{i}\right)
$$

where $R^{*}=\frac{x+\lambda}{1+\lambda}$. With $\tau^{1}=R^{*} g^{*}, k^{1 *}=k^{2 *}$ and $b^{1 *}=B^{*} / \Delta$ clearly satisfy the first order conditions. Thus the equilibrium level of per capita storage $\left(k^{*}\right)$ satisfies

$$
u^{\prime}\left(\omega^{y}-k^{*}(1+\lambda)\right)=R^{*} v^{\prime}\left(\omega^{o}+k^{*}(x+\lambda)\right) .
$$

Given the strict concavity of $u(\cdot)$ and $v(\cdot)$, and $\omega^{y}$ sufficiently larger than $\omega^{o}$, there exists a unique $k^{*} \geq 0$ which solves this condition.

We now turn to the incentives of the central bank. We argue that if the region does not set taxes to pay its debt obligation, then the central bank will not monetize. To see why, from (25) and $k^{1 *}=k^{2 *}$, the consumption levels of agents are equal if the CB allows a default. However, the allocation under monetization

\footnotetext{
${ }^{25}$ Recall we assume $b^{2 *}=0$ along the equilibrium path.
} 
provides greater consumption for region 1 agents since they bear only a fraction of the inflation tax and receive full repayment of their debt.

Yet, the total consumption of the old is the same, regardless of default or monetization. Under default, total consumption of the old agents is

$$
\omega^{o}+k^{*}(x+\lambda)
$$

Under monetization, total consumption is

$$
\omega^{o}+k^{*}(x+\lambda)+\lambda(\tilde{\pi}-1) \bar{k}^{*}+B^{*} R^{*} .
$$

where the rate of inflation is determined from the money creation needed to finance the bail-out as in (13). Thus if the monetary authority deviates and bails-out the region, the resulting inflation cancels out the last two terms in (29). Hence total consumption is the same regardless of default or bail-out. ${ }^{26}$ Since a bail-out leads to a less equitable consumption distribution, the CB will prefer default to monetization.

Given that the $\mathrm{CB}$ will not monetize the debt, the regional government will tax rather than default. This allows them to avoid the infinitesimal default penalty, $\kappa$. Under both regional taxation and default, the consumption of the region 1 old is given by $\omega^{o}+k^{*}(x+\lambda)$.

\subsection{Choice of $B^{*}$}

The equilibria described in the previous section take the steady state level of region 1 debt, $B^{*}$, as given. We now explore the determination of this level of debt.

Let $V(B)$ be the welfare of a region 1 agent if the stock of debt is $B$. In the Ricardian equilibrium, the choice of $B$ is, by construction, irrelevant for the welfare of region 1 agents. But in the monetization equilibrium, this is not the case. If one takes, for example, the perspective that the equilibrium will be determined by a sunspot process, then $V(B)$ places some weight on the monetization equilibrium and the remaining probability on the Ricardian equilibrium. ${ }^{27}$ Since welfare of region 1 agents is independent of $B$ in the Ricardian equilibrium, the only effect of $B$ occurs when the monetization equilibrium is selected. Thus we focus our discussion of the choice of $B$ assuming the selection of the monetization equilibrium.

So consider

$$
V(B)=u\left(\omega^{y}+\frac{B}{\Delta}-s\right)+v\left(\omega^{o}+s \tilde{R}(B)\right) .
$$

This is the level of lifetime expected utility for a representative region 1 agent in an equilibrium with monetization. Here $B$ is the level of debt per capita so that $\frac{B}{\Delta}$ is the level of debt, and thus the transfer in youth, per young region 1 agent. The function $\tilde{R}(B)$ is the return on savings if the stock of debt is $B$ from the equilibrium with monetization, see (13). Our main result is that the regional government will prefer a positive level of transfers given the positive probability that the central bank will bail-out this obligation.

\footnotetext{
${ }^{26}$ This result could have been anticipated in a stationary monetary equilibrium, where the real money balances of young agents, which finance the returns on old agents money holdings, are invariant to default or bail-out on debt held by the previous generation.

${ }^{27}$ The timing might be as follows. The regional government chooses $B$ and then a sunspot occurs which selects from the set of equilibria insofar as young agents condition their portfolio choice on the sunspot. This timing may occur each period or just at the start of time.
} 
Proposition 5 The solution to (30) entails $B>0$.

Proof. Using the envelope condition and region 1 agents' optimal choice of $s$ given $B$ and $\tilde{R}(B)$, the optimal choice of $B$ by the region 1 government satisfies

$$
V^{\prime}(B)=v^{\prime}\left(c^{o}\right)\left[\frac{\tilde{R}(B)}{\Delta}-s \tilde{R}^{\prime}(B)\right]=0
$$

To show $V^{\prime}(0)>0$, we view both $\tilde{R}$ and $\tilde{\pi}$ as functions of $B$, using $\tilde{R}=\frac{x+\lambda \tilde{\pi}}{1+\lambda}$ and (13) rewritten as

$$
\lambda \bar{k}(\tilde{R})(1-\pi)=\tilde{R} B
$$

Taking derivatives to calculate $\tilde{R}^{\prime}(B)$, and evaluating that derivative at $B=0$, where $\tilde{\pi}=1$, yields

$$
\tilde{R}^{\prime}(0)=-\frac{\tilde{R}(0)}{(1+\lambda) \bar{k}(\tilde{R}(0))}
$$

Substituting this into (31), recalling that with no debt issued $s^{1}=(1+\lambda) k^{1}$, yields

$$
V^{\prime}(0)=v^{\prime}\left(c^{o 1}\right) \tilde{R}(0)\left[\frac{1}{\Delta}-\frac{k^{1}}{\bar{k}}\right]
$$

Since $k^{1}=\bar{k}$ in a symmetric steady state with $B=0, V^{\prime}(0)$ is positive when $\Delta<1$. Thus the optimal policy of the region 1 government will entail a positive level of $B$.

Finally, we informally consider the situation where each of the two regions makes a favorable transfer to its agents, hoping to shift the debt payment to the central bank. It might appear that the ex-post incentive for consumption equality by the central bank will no longer motivate a bail-out once both regions issue debt. If so, then such symmetric regional behavior could, by itself, eliminate the free riding problem. However, the central bank's choice of a bail-out or default are obtained region by region, depending on the move made by that region, holding the other region's decision fixed. Suppose, for instance that both regions made a transfer in period 1, anticipating a bail-out in period 2. The CB's choice in period 2 between a bail-out and default is made for each region separately, and thus considers only the amount of redistribution in a bail-out relative to default regarding the debt of that particular region. Consequently, equally profligate behavior of both regions will not eliminate the free riding problem. ${ }^{28}$

\section{Policy Implications}

The two steady state equilibria characterized above have very different welfare implications for agents in the two regions. Agents in region 1 strictly prefer the monetization equilibrium while those in region 2 prefer the equilibrium with regional taxation. Thus, as indicated by Proposition 5 , the region 1 will increase the level of $B$ above zero and will try to support the equilibrium with monetization. In contrast, agents in region 2 would act to limit region 1 and eliminate the monetization equilibrium. We consider proposed policy measures from the perspective of these two groups of agents.

\footnotetext{
${ }^{28}$ We are grateful to Eddie Dekel for discussions this point.
} 
In this discussion it is also useful to recall the benchmark planner's solution. As in the discussion of the real game, the ex ante optimal allocation entails equal consumption across regions in all periods of agent's lives. This reflects the symmetry of the economy, the strict concavity of $u(\cdot)$ and $v(\cdot)$ and the use of population weights in the planner's objective function. The planner's solution can be decentralized either by the selection of the Ricardian equilibrium or when $B^{*}=0$. Thus the policy remedies can also be viewed as devices for supporting the planner's solution.

\subsection{Restrictions on debt}

We consider two types of restrictions. The first is on the total size of the regional debt and the second is on the holdings of that debt.

The first restriction is a debt limit. If $B^{*}$ is forced to be zero, then there is no monetization. Clearly a restriction of this form would be favored by region 2 agents.

Within Argentina, there have been numerous attempts to place limits on regional debt. But, not surprisingly, not all regions are in favor of these limits. Interestingly, recent negotiations with the International Monetary Fund have included a discussion of the regional fiscal situation. ${ }^{29}$ As far as the Stability and Growth Pact is concerned, many critics claim that the focus on actual deficits was ill-conceived and suggest that limits be imposed on national public debts.

The second restriction is on the holding of debt. Suppose there is a capital control which makes it prohibitively expensive for a private agent in region 2 or a financial intermediary intervening on his behalf to hold region 1 debt. Then this intervention implies that monetization is no longer a steady state and makes the Ricardian equilibrium the only steady state equilibrium. This restriction is in the interest of region 2 agents. Such restrictions on the holding of debt emulate a commitment device ruling out monetization.

In Argentina, the small-denomination debt of the Buenos Aires region, the so-called Patacones, issued in July 2002 allowed for the repayment of public obligations using these notes. But no other regions appear willing to accept these notes for payment of taxes. While this is not a policy that prohibits Patacones to be held outside of the Buenos Aires region, this policy clearly reduces their attractiveness for residents of other regions.

\subsection{Dollarization}

A commitment by the central bank not to bail-out any regional government would of course eliminate the monetization equilibrium. This is precisely the provision included in the Maastricht Treaty in the case of the EMU. But of course, this begs the question: what is the basis of this commitment power?

There is a more drastic measure, which has been recently widely discussed both by policymakers and economists: dollarization. This entails the complete surrender of monetary sovereignty, say by Argentina to the U.S., and not just restrictions on the supply of money. ${ }^{30}$ Clearly dollarization eliminates the possibility

\footnotetext{
${ }^{29}$ Details are available on the recent agreement between the IMF and Argentina, http://www.mecon.gov.ar.

${ }^{30}$ Cooper and Kempf (2001) explores the benefits of dollarization as a substitute for the commitment power of a central bank in a multi-region economy (call it "Argentina") without regional debt.
} 
of monetization by the Argentine central bank. But there are two important caveats.

First, there is still the possibility that the Argentine central government will bail-out by means of central taxes. This corresponds to the real game analysis in section 2. As we have shown in that section, there are still multiple equilibria, indexed by the distribution of debt holding across regions. Hence dollarization per se does not eliminate the multiplicity of equilibria, nor does it eliminate the ability of a regional government to exert (ex post) pressure on the central government.

Second, under dollarization, a version of the multi-region monetary economy studied above reappears at the world level. Suppose that it is Argentina that dollarizes and adopts the currency issued by the U.S. central bank. Assume that prior to dollarization, the U.S. had succeeded in eliminating pressures by the states on the federal government. ${ }^{31}$ Now with dollarization, the U.S. is like region 1 in the model of section 3 and Argentina now behaves as the region 2 passive government and does not issue debt. There is one important difference though: the U.S. central bank does not include the welfare of Argentina in its objective.

Clearly there is now a gain to monetization of the debt by the U.S. central bank since part of this tax will be paid by citizens of Argentina. Does this imply that the U.S. central bank will be willing to monetize in order to help U.S. citizens through an by inflation tax partly paid by Argentina? More generally, what are the consequences of dollarization for the existence of multiple equilibria in the world economy?

To study these issues we consider a world economy formed of the U.S. and Argentina. Under dollarization the only currency used in the world economy is the dollar, issued by the U.S. central bank, here called the FED. The U.S. Treasury is the sole active government (equivalent to Region 1 in the previous example), making transfers to young U.S. agents by issuing debt and possibly taxing its old agents. Moreover we assume that the FED and the Treasury only care about the welfare of U.S. citizens. Variables with the superscript 1 now refer to the American economy, variables with the superscript 2 refer to the Argentine economy. We denote by $\Delta$ the fraction of the world population in the U.S. A fraction $\theta$ of the amount of debt issued by the U.S. government $B^{*}$ is equally held by U.S. agents.

We find that dollarization indeed may support the monetization equilibrium. This is true if a sufficiently large fraction of the debt is held in the U.S. Then the FED may be induced to bail-out the U.S. government, and so doing will harm Argentine citizens who pay the inflation tax. In other words, dollarization does not solve per se the possibility of monetization. Again, the issue of debt distribution is crucial for the definition of the equilibrium in this economy. We also find that there is no longer a Ricardian equilibrium. The FED will always prefer to monetize and thus the U.S. government never levies a tax on U.S. citizens.

In effect, dollarization solves the multiplicity of monetary equilibria but by eliminating the virtuous one! These results are now derived formally.

\subsubsection{The monetization equilibrium}

We now construct a monetization equilibrium in which the FED bails-out the U.S. Treasury. Interestingly, the conditions for this type of equilibrium are quite different from those given in Proposition 3. Instead of a

\footnotetext{
${ }^{31}$ Exactly how this is done within the U.S. is an open question, but for now we assume that the central U.S. government has adequate commitment relative to its states.
} 
monetization equilibrium requiring that region 1 agents hold a small fraction of the debt, under dollarization the bail-out equilibrium requires that region 1 agents hold a large fraction of the debt.

Proposition 6 Under dollarization, for a given value of $B^{*}$, there exists a monetization equilibrium for $\theta$ sufficiently close to 1.

Proof. To characterize the monetarization equilibria, we check the incentives of the U.S. Treasury and the FED. Beginning with the FED, note that it takes into consideration the utility of old region 1 (American) agents only. Hence the FED's choice of default or bail-out depends only on the consumption of region 1 agents in these two outcomes. As in (17), the consumption levels of U.S. citizens under a monetized bail-out is

$$
c^{o 1 *}=\omega^{o}+b^{1 *} R^{*}+k^{1 *}\left(x+\lambda \tilde{\pi}^{*}\right)=\omega^{o}+k^{1 *}(x+\lambda)+R^{*} B^{*}\left(\frac{\theta}{\Delta}-\frac{k^{1 *}}{\bar{k}^{*}}\right),
$$

and by (19) for $i=1$ under default:

$$
\tilde{c}^{o 1}=\omega^{o}+k^{1 *}(x+\lambda) .
$$

The FED will choose to monetize rather than default iff $c^{o 1 *}>\tilde{c}^{o 1}$. From the above expressions:

$$
c^{o 1 *}>\tilde{c}^{o 1} \Leftrightarrow\left(\frac{\theta}{\Delta}-\frac{k^{1 *}}{\bar{k}^{*}}\right)>0 .
$$

Since $\bar{k}^{*} \equiv \Delta k^{1 *}+(1-\Delta) k^{2 *}$, this inequality holds for $\theta=1$. By continuity, it holds for $\theta$ near 1 .

Therefore when $\theta$, the fraction of debt held by U.S. residents, is sufficiently large, the FED will monetize the U.S. debt. This is preferred by the Treasury since the difference in consumption level under bail-out exceeds that under taxation of U.S. citizens, as in (21). Thus for $\theta$ near 1, there is a monetization equilibrium.

The relative gain of a bail-out over default from the FED's perspective depends on the relative inflation tax burden on U.S. residents. The more Argentine residents hold dollars, the more they bear of the inflation tax. The demand for money is proportional to the amount of capital held by Argentine residents. Therefore the higher is $\theta$, the smaller is the share of capital held by U.S. citizens and the larger is the inflation tax borne by Argentina.

Clearly this is a cost of dollarization for Argentine citizens, since they bear not only any Argentine taxes to finance their own public goods, but also the inflation tax for the benefit of U.S. citizens. Cooper and Kempf (2001) discuss the implications of a treaty between the U.S. and Argentina as an incentive device on the U.S. central bank to limit the inflation tax.

Note that we obtained the opposite result than that of the previous section. There, the monetary authority, caring about equalizing consumption among regions, chooses the best way to redistribute from region 1 to region 2. In the case of dollarization, as the FED cares only about the U.S. welfare, it chooses the best way to redistribute from region 2 to region 1 .

\subsubsection{The Ricardian equilibrium}

We now turn to the possibility of a Ricardian equilibrium. In contrast to Section 3, there is no Ricardian equilibrium in this economy. 
Proposition 7 Under dollarization, for a given value of $B^{*}$, there is no Ricardian equilibrium.

Proof. In a Ricardian equilibrium, agents in region 1 anticipate future taxes and thus $s^{1}=s^{2}+\frac{B^{*}}{\Delta}$. As both the U.S. Treasury and the FED have the same objective of maximizing the consumption of old U.S. agents, the outcome of the game played each period will provide to U.S. agents the maximal consumption level.

In a Ricardian equilibrium, the U.S. Treasury levies a tax on U.S. citizens so that the consumption of a region 1 old agent is:

$$
\hat{c}^{o 1}=\omega^{o}+k^{1 *}(x+\lambda)+\frac{R^{*} B^{*}}{\Delta}(\theta-1) .
$$

Suppose instead that the U.S. Treasury does not levy the tax. The consumption levels under a bail-out (viewed as a defection for a candidate Ricardian equilibrium) and a default are given in (35) and (36), respectively, where the values of $k^{i *}$ in these expressions is part of the candidate Ricardian equilibrium.

Comparing (38) and (35), bail-out dominates regional taxation for region $1, c^{o 1} \geq \hat{c}^{o 1}$, since $\frac{k^{1}}{k} \leq \frac{1}{\Delta}$. And the inequality is strict if $k^{2 *}>0$. If $k^{2 *}=0$, then the consumption under default is higher than that under bail-out: $\tilde{c}^{o 1} \geq c^{o 1}$ and thus default dominates the consumption under taxation. Thus there is no equilibrium in which the U.S. Treasury taxes U.S. citizens since it will always prefer the outcome under either a bail-out or a default.

This result stands in contrast to that in Proposition 4 in which there was an isolated Ricardian equilibrium in which region 1 agents held all of that debt. In that equilibrium, the central bank preferred default to a bail-out since the allocation under a default was equal across old agents in the two regions. But, under dollarization, the objective of the FED coincides with the U.S. Treasury and so the payment of taxes by U.S. citizens is dominated by either a bail-out or a default.

\section{Conclusion}

The goal of this paper was to determine the impact of issuing debt by a regional government in a monetary union. Recent events in Argentina, (the issue and circulation of small denomination bonds by some provinces, such as the Patacones), and in Europe, (the de facto demise of the Stability and Growth Pact at the end of 2003), prove the necessity of a better understanding of how "soft" is regional debt in monetary unions. Two leading views are relevant: (i) the debt is just a claim on future tax revenues and (ii) the debt is "like" money and hence printing it is tantamount to the printing of fiat money and thus was inflationary.

Our analysis indicates that both interpretations are consistent with an equilibrium of our monetary model. The multiplicity reflects a commitment problem on the part of the central government. Without commitment, the central government will ex post always redistribute consumption to achieve greater equality in consumption across different regions. Depending on the distribution of the holding of the regional government debt, this desire for redistribution may lead the central government to bail-out a region or it may lead the central government to allow default. In equilibrium, the distribution of the holdings of regional governments' debt has powerful effects on the incentives for the central government. The more even is this distribution, the more likely it is that the central government will prefer a bail-out to a costly default. 
The commitment problem of the central government has some important incentive effects on the regions. A bail-out creates a free-rider problem in that regional governments will have an incentive to run inefficiently large deficits in anticipation of a government bail-out. ${ }^{32}$ Not surprisingly, other agents in the economy will have an incentive to erect impediments to this free-rider problem including: debt restrictions, limits on the holding of debt by other regions and even dollarization.

As a final note, the analysis did not require that the regional debt be small denomination. Nonetheless the paper does provide an explanation for the choice of denomination. As argued above, monetization of the regional debt is more likely if that debt is widely held. From that perspective, small denomination debt may be more likely to circulate outside a narrow set of individuals and banks within a region. Thus a regional government may perceive a gain to issuing small denomination debt.

\section{References}

Aizenman, J. (1992): "Competitive Externality and Optimal Seigniorage," Journal of Money, Credit and Banking, 24, 61-71.

Bergstrom, T. (1989): "A Fresh Look at the Rotten Kid Theorem- and Other Household Mysteries," Journal of Political Economy, 97(5), 1138-59.

Bruce, N., and M. Waldman (1990): "The Rotten-Kid Theorem Meets the Samaritans Dilemma," Quarterly Journal of Economics, 105, 155-65.

Chari, V. V., And P. Kehoe (1998): "On the Need for Fiscal Constraints in a Monetary Union," Federal Reserve Bank of Minneapolis, Working Paper \#589.

(2002): "Time Inconsistency and Free-Riding in a Monetary Union," Federal Reserve Bank of Minneapolis, Staff Report \# 308.

Cooper, R., and H. Kempf (2000): "Designing Stabilization Policy in a Monetary Union," NBER Working Paper \#7607, forthcoming Review of Economic Studies as "Overturning Mundell: Fiscal Policy in a Monetary Union".

(2001): "Dollarization and the conquest of hyperinflation in divided societies," Federal Reserve Bank of Minneapolis Quarterly Review, 25(3).

Inman, R. (2003): "Transfers and Bailouts: Enforcing Local Fiscal Discipline with Lessons from U.S.

Federalism," in Fiscal Decentralization and the Challenge of Hard Budget Constraint, ed. by G. S. E. J. Rodden, and J. Litvack. MIT Press.

\footnotetext{
${ }^{32}$ This point is brought out in the context of monetary unions in Chari and Kehoe (1998), Chari and Kehoe (2002) and Cooper and Kempf (2000). Interestingly, the free-rider problem can be shown to exist in our setting even when the central government can optimally choose a partial bail-out, where in the face of no payment by the region it selects a fraction of the regional debt that it pays off, allowing default on the remaining debt, (see Chari and Kehoe (2002)).
} 
LindBeck, A., And J. Weibull (1988): "Altruism and time consistency - the economics of fait accompli," Journal of Political Economy, 96(6), 1165-82.

Smith, B. (1994): "Efficiency and Determinacy of Equilibrium under Inflation Targeting," Economic Theory, $4(3), 327-44$.

Zarazaga, C. (1995): "Hyperinflations and Moral Hazard in the Appropriation of Seignorage," Federal Reserve Bank of Dallas, Working Paper 95-17. 


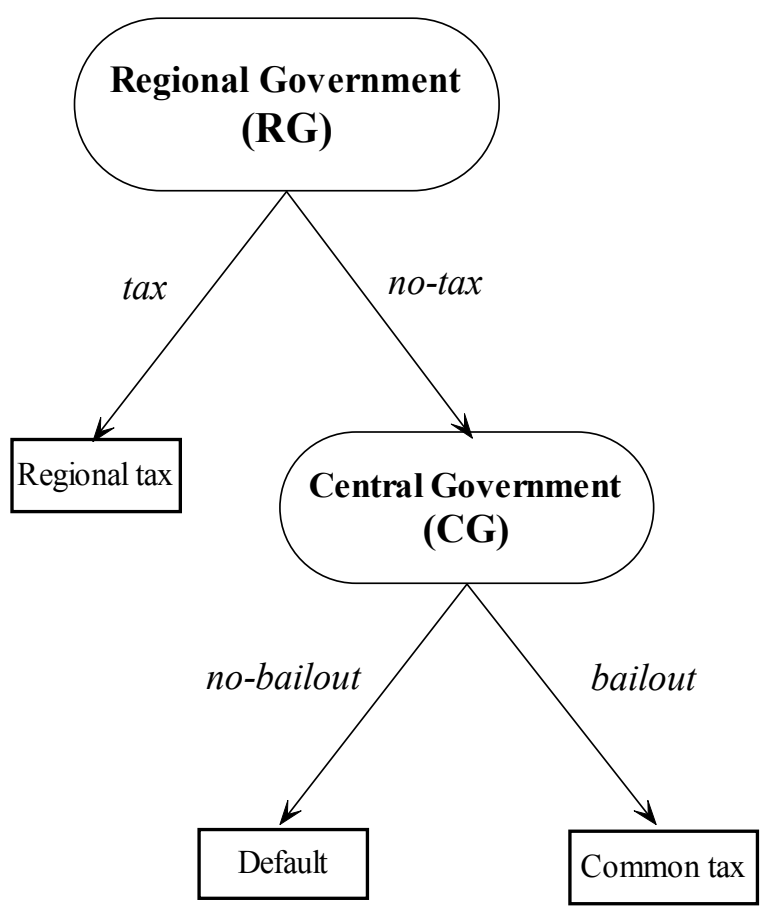

Figure 1: Game Structure

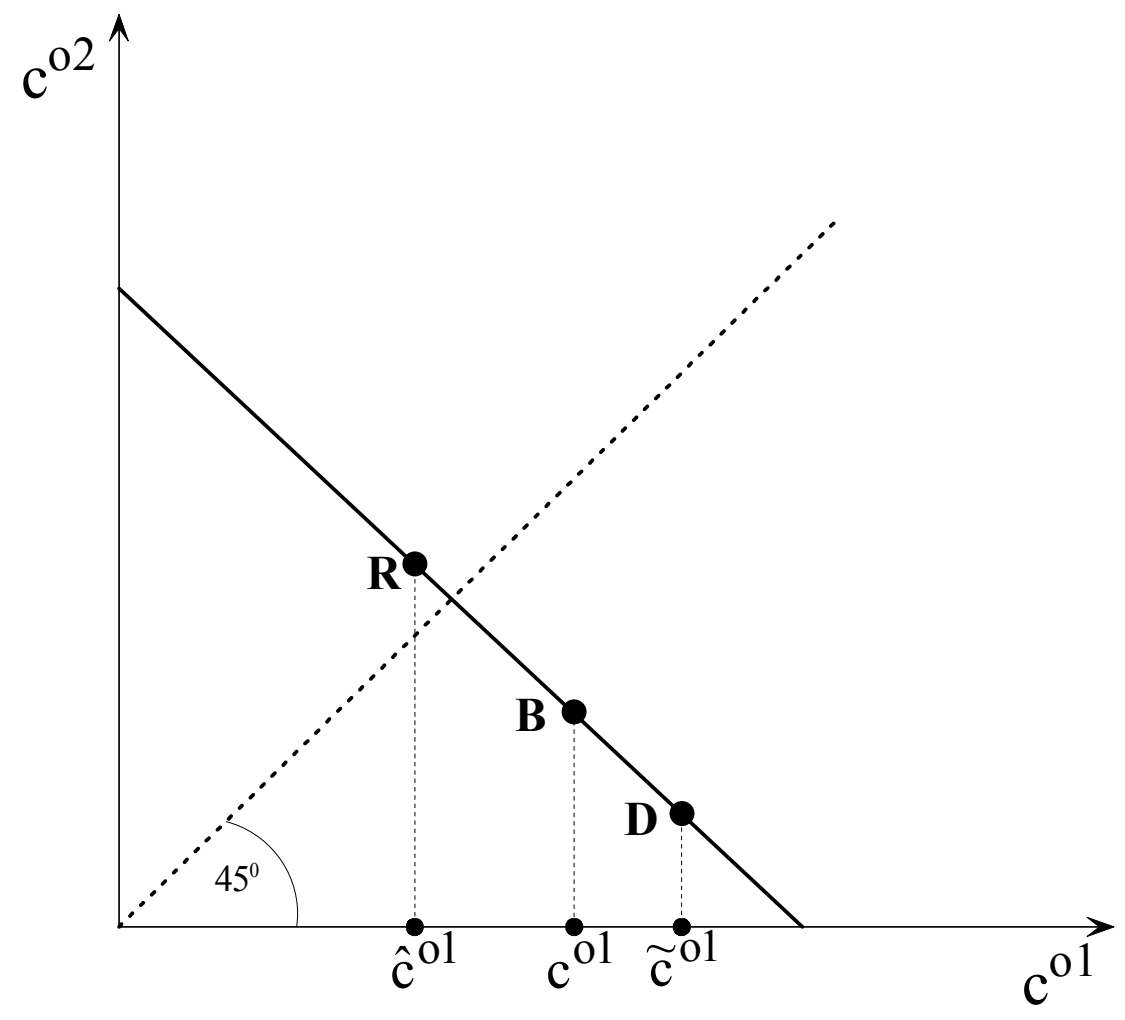

Figure 2: old-age consumption across regions 